OPEN ACCESS

Edited by:

Weiwen Zhang,

Tianjin University, China

Reviewed by:

Hada Wuriyanghan,

Inner Mongolia University, China

Jianping Xie,

Southwest University, China

${ }^{*}$ Correspondence:

Xiwen Chen

xiwenchen@nankai.edu.cn 0000-0002-6511-4709

Defu Chen

chendefu@nankai.edu.cn 0000-0002-1742-6011

Specialty section: This article was submitted to

Microbiotechnology,

a section of the journal

Frontiers in Microbiology

Received: 03 November 2020 Accepted: 28 December 2020

Published: 01 February 2021

Citation:

Xie J, Yan Z, Wang G, Xue W, Li C, Chen X and Chen D (2021) A

Bacterium Isolated From Soil in a Karst Rocky Desertification Region Has Efficient Phosphate-Solubilizing and Plant Growth-Promoting Ability.

Front. Microbiol. 11:625450 do: $10.3389 /$ fmicb.2020.625450

\section{A Bacterium Isolated From Soil in a Karst Rocky Desertification Region Has Efficient Phosphate-Solubilizing and Plant Growth-Promoting Ability}

\author{
Jinge Xie ${ }^{1}$, Zongqiang Yan ${ }^{1}$, Guifen Wang ${ }^{1}$, Wenzhi Xue ${ }^{2}$, Cong $\mathrm{Li}^{1}$, Xiwen Chen ${ }^{2 *}$ and \\ Defu Chen ${ }^{\text {* }}$
}

'Department of Genetics and Cell Biology, College of Life Sciences, Nankai University, Tianjin, China, ${ }^{2}$ Department of Biochemistry and Molecular Biology, College of Life Sciences, Nankai University, Tianjin, China

Phosphorus in the soil accessible to plants can easily be combined with calcium ion, the content of which is high in karst rocky desertification (KRD) regions, thereby resulting in a low utilization efficiency of phosphorus. The application of phosphate-solubilizing bacteria (PSB) from the KRD region would facilitate enhanced phosphate availability in the soil. In the present study, the strains belonging to Acinetobacter, Paraburkholderia, and Pseudomonas with efficient phosphate-solubilizing ability were isolated from fruit tree rhizosphere soils in KRD regions. Particularly, Acinetobacter sp. Ac-14 had a sustained and stable phosphate-solubilizing ability (439-448 mg/L, 48-120 h). Calcium carbonate decreased the phosphate-solubilizing ability in liquid medium; however, it did not affect the solubilization index in agar-solidified medium. When cocultivated with Arabidopsis thaliana seedling, Ac-14 increased the number of lateral roots, fresh weight, and chlorophyll content of the seedlings. Metabolomics analysis revealed that Ac-14 could produce 23 types of organic acids, majorly including gluconic acid and D-(-)-quinic acid. Expression of Ac-14 glucose dehydrogenase gene (gcd) conferred Pseudomonas sp. Ps-12 with a sustained and stable phosphate-solubilizing ability, suggesting that the production of gluconic acid is an important mechanism that confers phosphate solubilization in bacteria. Moreover, Ac-14 could also produce indole acetic acid and ammonia. Collectively, the isolated Ac-14 from KRD regions possess an efficient phosphate-solubilizing ability and plant growth-promoting effect which could be exploited for enhancing phosphorus availability in KRD regions. This study holds significance for the improvement of soil fertility and agricultural sustainable development in phosphorus-deficient KRD regions.

Keywords: phosphate-solubilizing bacteria, plant growth-promoting, Acinetobacter, karst rocky desertification, organic acid

\section{INTRODUCTION}

There are three karst centers worldwide: in the European Mediterranean, the Dinaric karst regions of the Balkan Peninsula, and in Southwest China. In karst regions, the processes of soil erosion, vegetation loss, exposure of rocks, and the appearance of a rocky landscape are termed as karst rocky desertification (KRD, Wang et al., 2004; Jiang et al., 2014). KRD is considered as one of the 
most severe ecological problems worldwide (Wang et al., 2004; Tang et al., 2019). The degraded environment and low productivity in KRD regions hinders local economic growth and affects the people living in these regions (Jiang et al., 2014). Karst topography is a special landscape that is developed on carbonate rocks such as limestone, dolomite, or marble, and rocky desertification mainly occurs in carbonate rocks areas. Bare carbonate rocks generally produce $\mathrm{Ca}^{2+}$ and $\mathrm{HCO}_{3}{ }^{-}$in soil (White, 1997), wherein $\mathrm{Ca}^{2+}$ can combine with $\mathrm{H}_{2} \mathrm{PO}_{4}{ }^{-}$to form insoluble phosphate, which is inaccessible for plants.

Phosphorus $(\mathrm{P})$ is one of the major essential macronutrients for plants and is an indispensable component of nucleic acids (RNA and DNA), proteins, phospholipids, and cofactors (such as ATP). To provide plants with nutritional requirements, $\mathrm{P}$ generally relies on the application of chemical $\mathrm{P}$ fertilizers to the soil. Nevertheless, these chemical $\mathrm{P}$ fertilizers are easily fixed by $\mathrm{Ca}^{2+}, \mathrm{Fe}^{3+}$, and $\mathrm{Al}^{3+}$ in the soil, thereby resulting in low utilization efficiency (Wei et al., 2018); on the other hand, extensive usage of chemical $\mathrm{P}$ fertilizer may lead to numerous environmental issues, such as soil compaction and water pollution, and may increase economic burden (Sharma et al., 2013; Wang et al., 2019). Considering the issue arising due to low efficiency of chemical $\mathrm{P}$ fertilizers, it is crucial to improve $\mathrm{P}$ availability in soil, particularly in the KRD regions.

Total $\mathrm{P}$ is abundant, but available $\mathrm{P}$ is generally low in soil (Wei et al., 2016). We previously reported that the community structure of rhizospheric bacteria is remarkably influenced by water-soluble phosphorus (WSP) in rocky desertification areas (Xie et al., 2019). Microorganisms play a pivotal role in the cycle of soil nutrients, wherein the phosphate-solubilizing bacteria (PSB) can convert insoluble phosphates into soluble forms that are available for plants. Recently, low-input agriculture has gained immense interest from researchers, with focus given to the development and use of commercial biological inoculants to the increase the availability of key nutrients, particularly $\mathrm{P}$, to crop plants (Owen et al., 2015). PSB have been isolated from various environmental areas, including solid waste compost, metal-contaminated soil, activated sludge, and saltern sediments (Park et al., 2011; Zhu et al., 2011; Wei et al., 2016; Yu et al., 2019); however, no report is available regarding PSB isolated from the fruit tree rhizosphere soil in KRD regions. As native PSB have the advantage of colonizing in the local soil (Wang et al., 2018), PSB strains isolated from KRD soil would, therefore, have special significance and could be utilized in KRD ecological restoration and agricultural development.

The mechanisms of PSB on phosphate solubilization are complex. The redox activity of microorganisms, production of $\mathrm{CO}_{2}$, secretion of siderophores, enzymes, and organic acid, and nitrogen assimilation were considered to be PSB mechanisms that could transform insoluble $\mathrm{P}$ to soluble forms (Rodríguez and Fraga, 1999; Sharma et al., 2013; Owen et al., 2015). In general, production of low molecular weight organic acids is the main phosphate-solubilizing mechanism of PSB (Rodríguez and Fraga, 1999; Ludueña et al., 2018). Gluconic acid has immense importance and is mainly produced by the glucose dehydrogenase (GCD) which is encoded by $g c d$ gene (Liang et al., 2020). Besides the solubilizing insoluble phosphates, most PSB can also produce plant growth-regulating substances, such as indole acetic acid (IAA) and ammonia, to promote plant growth (Ludueña et al., 2018; Wang et al., 2019).

To develop and restore the agricultural and ecological environment in KRD regions, it is necessary to isolate PSB strains that are suitable for the native soil that also present an efficient phosphate-solubilizing ability and plant growthpromoting effect in KRD soil. The present study aimed to isolate novel PSB strains from the rhizosphere soil of fruit trees in the KRD regions in Southwest China and to analyze characteristics and mechanisms of phosphate solubilization and plant growth-promotion. In this study, we isolated a strain of PSB (Acinetobacter sp. Ac-14) from the fruit tree rhizosphere soils in the KRD region which could solubilize phosphate and promote plant growth and found that gluconic acid plays an important role in maintaining sustained and stable phosphate solubilization. Our findings will provide a theoretical foundation for understanding the phosphate solubilization mechanism of PSB and offer a basis for the application and development of ecofriendly, high-yield agriculture in KRD regions.

\section{MATERIALS AND METHODS}

\section{Collection of Soil Samples and Isolation of PSB Strains}

Soil samples were collected from the rhizosphere soil of fruit tree in KRD and non-KRD (NKRD) regions (Table 1), according to the method described previously (Xie et al., 2019). After adding sterile distilled water (soil sample: water $=1: 10, \mathrm{w} / \mathrm{v}$ ), the samples were shaken at $180 \mathrm{r} / \mathrm{min}$ for $30 \mathrm{~min}$ under $28 \pm 2^{\circ} \mathrm{C}$. After serial dilution $\left(10^{-1}-10^{-6}\right)$ with sterile distilled water, 100 $\mu \mathrm{L}$ of soil solution was placed on modified National Botanical Research Institute's Phosphate (NBRIP) agar-solidified medium (Nautiyal, 1999, in Supplementary Material and Methods), and incubated at $28 \pm 2^{\circ} \mathrm{C}$ for 6 days. The strains with clear halos were selected, halo zone diameter (D) and colony diameter (d) were determined, and solubilization index (SI) (the ratio of $\mathrm{D} / \mathrm{d}$ ) was calculated to roughly evaluate their phosphate-solubilizing capacities (Teng et al., 2019). The isolated strains were purified with modified NBPIP and AT salts medium (Nautiyal, 1999, in Supplementary Material and Methods) and stored with 20\% glycerol in a refrigerator at $-70^{\circ} \mathrm{C}$.

\section{Identification and Characterization of the Isolated PSB Strains}

$16 \mathrm{~S}$ rDNA sequencing was used to identify the isolated strains (Zhu et al., 2011; Biswas et al., 2018; Yu et al., 2019). Genomic DNA was extracted from the isolated strains and the 16S rDNA was amplified via polymerase chain reaction (PCR) using universal primers $27 \mathrm{~F}$ ( $5^{\prime}$-agrgtttgatcmtggctcag- $3^{\prime}$, where $\mathrm{r}$, a or g; $\mathrm{m}$, a or $\mathrm{c}$ ) and $1522 \mathrm{R}\left(5^{\prime}\right.$-aaggaggtgatccarccrca- $\left.3^{\prime}\right)$. Each PCR reaction comprised $1.2 \mu \mathrm{L}$ deoxynucleotide triphosphate (dNTPs, each $2.5 \mathrm{mM}$ ), $1 \mu \mathrm{L}$ template DNA, $0.18 \mu \mathrm{L}$ each primer $(10 \mu \mathrm{M})$, and $0.075 \mu \mathrm{L}$ Ex DNA polymerase $(5 \mathrm{U} / \mu \mathrm{L}$, TaKaRa Co., Ltd., Dalian, China). The products were detected 


\begin{tabular}{|c|c|c|c|c|c|c|c|c|c|c|c|c|c|c|}
\hline \multirow[t]{2}{*}{ Soil No. } & \multirow[t]{2}{*}{ Region } & \multirow[t]{2}{*}{ Code } & \multirow[t]{2}{*}{ Latitude } & \multirow[t]{2}{*}{ Longitude } & \multirow[t]{2}{*}{$\begin{array}{l}\text { Altitude/ } \\
\text { m }\end{array}$} & \multirow[t]{2}{*}{ County, province } & \multirow[t]{2}{*}{ Tree species } & \multirow[t]{2}{*}{$\begin{array}{c}\text { Tree } \\
\text { age/year }\end{array}$} & \multirow[t]{2}{*}{$\begin{array}{c}\text { No. of } \\
\text { isolated PSB }\end{array}$} & \multirow[t]{2}{*}{$\begin{array}{c}\text { No. of } \\
\text { sequenced PSB }\end{array}$} & \multicolumn{3}{|c|}{$\begin{array}{l}\text { PSB species by } \\
\text { 16S rDNA }\end{array}$} & \multirow[b]{2}{*}{ Others } \\
\hline & & & & & & & & & & & Ac. & Pa. & Ps. & \\
\hline 1 & $\mathrm{KRD}$ & EJ1 & $30^{\circ} 18^{\prime} 49^{\prime \prime} \mathrm{N}$ & $109^{\circ} 29^{\prime} 07^{\prime \prime} \mathrm{E}$ & 400 & Enshi, Hubei & Citrus reticulata & 3 & 39 & 2 & 0 & 0 & 2 & 0 \\
\hline 2 & & GJ1 & $28^{\circ} 01^{\prime} 44^{\prime \prime} \mathrm{N}$ & $108^{\circ} 28^{\prime} 52^{\prime \prime} \mathrm{E}$ & 593 & Yinjiang, Guizhou & Citrus reticulata & 2 & 36 & 3 & 0 & 0 & 2 & 1 \\
\hline 3 & & GJ2 & $28^{\circ} 01^{\prime} 46^{\prime \prime} \mathrm{N}$ & $108^{\circ} 28^{\prime} 55^{\prime \prime} \mathrm{E}$ & 588 & Yinjiang, Guizhou & Citrus reticulata & 2 & 43 & 11 & 6 & 0 & 0 & 5 \\
\hline 4 & & GJ3 & $28^{\circ} 01^{\prime} 49^{\prime \prime} \mathrm{N}$ & $108^{\circ} 28^{\prime} 54^{\prime \prime} \mathrm{E}$ & 587 & Yinjiang, Guizhou & Citrus reticulata & 5 & 104 & 17 & 1 & 0 & 13 & 3 \\
\hline 5 & & GY1 & $28^{\circ} 01^{\prime} 25^{\prime \prime} \mathrm{N}$ & $108^{\circ} 29^{\prime} 07^{\prime \prime} \mathrm{E}$ & 517 & Yinjiang, Guizhou & Citrus maxima (Burm) Merr. & 10 & 68 & 2 & 0 & 0 & 2 & 0 \\
\hline 6 & & HT1 & $28^{\circ} 27^{\prime} 40^{\prime \prime} \mathrm{N}$ & $109^{\circ} 29^{\prime} 52^{\prime \prime} \mathrm{E}$ & 550 & Huayuan, Hunan & Amygdalus persica L. & 3 & 19 & 2 & 0 & 0 & 2 & 0 \\
\hline 7 & & $\mathrm{HZ1}$ & $28^{\circ} 26^{\prime} 33^{\prime \prime} \mathrm{N}$ & $109^{\circ} 28^{\prime} 49^{\prime \prime} \mathrm{E}$ & 550 & Huayuan, Hunan & Ziziphus jujuba Mill. & 3 & 17 & 4 & 0 & 0 & 4 & 0 \\
\hline 8 & & NY1 & $28^{\circ} 12^{\prime} 38^{\prime \prime} \mathrm{N}$ & $112^{\circ} 35^{\prime} 42^{\prime \prime} \mathrm{E}$ & 388 & Ningxiang, Hunan & Citrus aurantium $\mathrm{L}$. & 10 & 22 & 2 & 0 & 0 & 2 & 0 \\
\hline 9 & & NY2 & $28^{\circ} 12^{\prime} 38^{\prime \prime} \mathrm{N}$ & $112^{\circ} 35^{\prime} 42^{\prime \prime} \mathrm{E}$ & 388 & Ningxiang, Hunan & Citrus aurantium $\mathrm{L}$. & 10 & 17 & 1 & 0 & 0 & 0 & 1 \\
\hline 10 & & WG1 & $30^{\circ} 46^{\prime} 16^{\prime \prime} \mathrm{N}$ & $114^{\circ} 12^{\prime} 24^{\prime \prime} \mathrm{E}$ & 21 & Wuhan, Hubei & $\begin{array}{l}\text { Osmanthus fragrans } \\
\text { (Thunb.) Lour. }\end{array}$ & 5 & 56 & 5 & 0 & 0 & 5 & 0 \\
\hline 11 & & $\mathrm{XB1}$ & $26^{\circ} 32^{\prime} 08^{\prime \prime} \mathrm{N}$ & $110^{\circ} 45^{\prime} 41^{\prime \prime} \mathrm{E}$ & 365 & Xinning, Hubei & Castanea mollissima BL. & 5 & 30 & 5 & 0 & 4 & 0 & 1 \\
\hline 12 & & XQ1 & $26^{\circ} 39^{\prime} 46^{\prime \prime} \mathrm{N}$ & $110^{\circ} 57^{\prime} 52^{\prime \prime} \mathrm{E}$ & 427 & Xinning, Huibei & Citrus sinensis L. Osbeck & 10 & 59 & 2 & 0 & 0 & 1 & 1 \\
\hline 13 & & XQ2 & $26^{\circ} 31^{\prime} 46^{\prime \prime} \mathrm{N}$ & $110^{\circ} 45^{\prime} 03^{\prime \prime} \mathrm{E}$ & 353 & Xinning, Hubei & Citrus sinensis L. Osbeck & 10 & 16 & 5 & 0 & 0 & 1 & 4 \\
\hline 14 & & $\mathrm{YH} 1$ & $29^{\circ} 00^{\prime} 33^{\prime \prime} \mathrm{N}$ & $108^{\circ} 57^{\prime} 31^{\prime \prime} \mathrm{E}$ & 333 & Youyang, Chongqing & $\begin{array}{l}\text { Zanthoxylum schinifolium } \\
\text { Sieb. et Zucc }\end{array}$ & 5 & 27 & 0 & 0 & 0 & 0 & 0 \\
\hline 15 & & $Y Y 1$ & $28^{\circ} 56^{\prime} 38^{\prime \prime} \mathrm{N}$ & $109^{\circ} 56^{\prime} 38^{\prime \prime} \mathrm{E}$ & 330 & Youyang, Chongqing & Citrus maxima (Burm.) Merr. & 1 & 17 & 6 & 1 & 0 & 0 & 5 \\
\hline 16 & NKRD & $\mathrm{CX} 1$ & $43^{\circ} 54^{\prime} 13^{\prime \prime} \mathrm{N}$ & $125^{\circ} 20^{\prime} 31^{\prime \prime} \mathrm{E}$ & 187 & Changchun, Jilin & Armeniaca vulgaris Lam. & 10 & 59 & 11 & 0 & 0 & 11 & 0 \\
\hline 17 & & CX2 & $43^{\circ} 54^{\prime} 13^{\prime \prime} \mathrm{N}$ & $125^{\circ} 20^{\prime} 37^{\prime \prime} \mathrm{E}$ & 211 & Changchun, Jilin & Armeniaca vulgaris Lam. & 20 & 107 & 8 & 0 & 0 & 8 & 0 \\
\hline 18 & & $\mathrm{CX} 3$ & $43^{\circ} 49^{\prime} 13^{\prime \prime} \mathrm{N}$ & $125^{\circ} 16^{\prime} 41^{\prime \prime} \mathrm{E}$ & 251 & Changchun, Jilin & Armeniaca vulgaris Lam. & 10 & 69 & 3 & 0 & 0 & 2 & 1 \\
\hline Total & & / & / & / & / & / & / & / & 805 & 89 & 8 & 4 & 55 & 22 \\
\hline
\end{tabular}

KRD, karst rocky desertification; NKRD, non-karst rocky desertification; Ac, Acinetobacter; Pa, Paraburkholderia; Ps, Pseudomonas. 
via agarose gel electrophoresis and the $1.5 \mathrm{~kb}$ band was purified using a Gel/PCR extraction kit (Tiangen Biotech Co., Ltd., Beijing, China). The purified 16S rDNA fragment was ligated to pMD19-T Simple vector (TaKaRa Co., Ltd., Dalian, China), and then transformed into Escherichia coli DH5 $\alpha$ competent cells. Positive clones were selected for sequencing, and the conservative sequences from numerous sequences were used for BLASTx with the NCBI database to identify the species. A phylogenetic tree was constructed using the neighbor-joining method with MEGA ver. X.

Strains were inoculated in Luria-Bertani (LB) medium (tryptone $10 \mathrm{~g} / \mathrm{L}$, yeast extract $5 \mathrm{~g} / \mathrm{L}$, and $\mathrm{NaCl} 5 \mathrm{~g} / \mathrm{L}$ ) and incubated overnight under $180 \mathrm{r} / \mathrm{min}$ at $28 \pm 2^{\circ} \mathrm{C}$. Thereafter, the cells were collected via centrifugation at $5,000 \mathrm{r} / \mathrm{min}$ for $5 \mathrm{~min}$. After washing with phosphate buffer saline $(\mathrm{NaCl} 8 \mathrm{~g} / \mathrm{L}$, $\mathrm{KCl} 0.2 \mathrm{~g} / \mathrm{L}, \mathrm{Na}_{2} \mathrm{HPO}_{4} 1.44 \mathrm{~g} / \mathrm{L}, \mathrm{KH}_{2} \mathrm{PO}_{4} 0.24 \mathrm{~g} / \mathrm{L}, \mathrm{pH}=7.4$ ) 2-3 times, the samples were fixed with $2.5 \%$ glutaraldehyde at $4^{\circ} \mathrm{C}$ for at least $8 \mathrm{~h}$, dehydrated gradually with $30,50,70,80$, 90, and $100 \%$ ethanol (twice), and then dissolved in absolute ethanol. The solution was dropped on the cover glass, dried at room temperature, and fixed to the scanning electron microscope (SEM) column after spraying gold. The morphology was scanned under SEM (QUANTA 200, FEI Company, Hillsboro, OR, United States). In total, 30 cells from each sample were randomly selected to measure the cell size using ImageJ. Gram staining was performed using the Gram stain kit (Beijing Solarbio Science and Technology Co., Ltd., Beijing, China).

\section{Evaluation of Phosphate-Solubilizing Characteristics of the Isolated PSB Strains}

The sequenced PSB strains were incubated in LB medium until $A_{600}=1.8$; thereafter, $10 \%(\mathrm{v} / \mathrm{v})$ inoculum amount was transferred to liquid NBRIP medium and incubated under 180 $\mathrm{r} / \mathrm{min}$ at $28 \pm 2^{\circ} \mathrm{C}$ for $24 \mathrm{~h}$. The cultures were centrifuged at $8,000 \mathrm{r} / \mathrm{min}$ for $10 \mathrm{~min}$ and the $\mathrm{P}$ content of the supernatant was detected via Mo-blue method (Murphy and Riley, 1962). The NBRIP medium inoculated with the same amount of LB was used as a negative control.

Moreover, the $\mathrm{pH}$ value of the supernatant and the $A_{600}$ value of bacteria were determined at $6,12,24,48,72,96$, and $120 \mathrm{~h}$ after inoculation. $\mathrm{pH}$ was detected by a $\mathrm{pH}$ meter $\mathrm{PH} 400$, Alalis Instruments Technology Co., Ltd., Shanghai, China). $A_{600}$ value was measured by a spectrophotometer (TU-1810S, Beijing Purkinje General Instrument Co., Ltd., Beijing, China). To eliminate the effect of calcium phosphate in the culture medium on $A_{600}$ value, the precipitate obtained by centrifuging the cultures was washed with equal volumes of $0.1 \mathrm{mM}$ hydrochloric acid (Xiang et al., 2011).

Different concentrations of calcium carbonate $\left(\mathrm{CaCO}_{3}\right)(0$, $0.5,1.0,1.5$, and $2.0 \mathrm{~g} / \mathrm{L}$ ) were added to NBRIP liquid medium to detect its effect on the growth of the isolated PSB strains. The SI value was evaluated on NBRIP agar-solidified medium containing $\mathrm{CaCO}_{3}$.

To evaluate the $\mathrm{NH}_{4}{ }^{+}$assimilation of Acinetobacter sp. Ac14, equal amounts of $\mathrm{NH}_{4} \mathrm{Cl}, \mathrm{NaNO}_{3}$, and $\mathrm{KNO}_{3}$ were used to substitute $\left(\mathrm{NH}_{4}\right)_{2} \mathrm{SO}_{4}$ in the NBRIP medium. After $24 \mathrm{~h}$ culture, the soluble $\mathrm{P}$ content, $\mathrm{pH}$ value, and $A_{600}$ value of the supernatant of the cultures were determined.

\section{Evaluation of Plant Growth-Promoting Ability of the Isolated PSB Strains}

Arabidopsis thaliana (Columbia) seeds were sterilized with 3\% sodium hypochlorite for $1 \mathrm{~min}$, washed with sterile water for 5-6 times, and sown on 1/2 Murashige and Skoog (MS) [Murashige and Skoog basal medium with vitamins (Duchefa Biochemie, NLD) $2.202 \mathrm{~g} / \mathrm{L}, 2$-(N-morpholino) ethanesulfonic acid (Genview, United States) $0.5 \mathrm{~g} / \mathrm{L}$ and sucrose $10 \mathrm{~g} / \mathrm{L}$, $\mathrm{pH}=5.7]$ agar-solidified medium. After preserving at $4^{\circ} \mathrm{C}$ for 3 days, the plates were vertically placed in a light incubator $\left(22^{\circ} \mathrm{C}, 16 \mathrm{~h}\right.$ light, $8 \mathrm{~h}$ dark) for 7 days. The seedlings were then transferred to NBRIP agar-solidified medium, and inoculated with PSB $\left(10 \mu \mathrm{L}, A_{600}=0.05\right)$ around the roots. The plates were positioned vertically and cultured in a light incubator. After cocultivation for 7 and 14 days, the number of lateral roots, primary root length, fresh weight, and chlorophyll content of the seedlings were measured. The chlorophyll content was determined according to the method described by $\mathrm{Xu}$ et al. (2018). The seedlings inoculated with LB were used as the control.

\section{Untargeted Metabolomics of Ac-14}

The Ac-14 strain was incubated in LB medium until $A_{600}=1.8$, and thereafter, $10 \%(\mathrm{v} / \mathrm{v})$ inoculum amount was transferred to liquid NBRIP medium and incubated under $180 \mathrm{r} / \mathrm{min}$ at $28 \pm 2{ }^{\circ} \mathrm{C}$ for $24 \mathrm{~h}$. The cultures were then centrifuged at $8,000 \mathrm{r} / \mathrm{min}$ for $10 \mathrm{~min}$, the supernatants were frozen in liquid nitrogen, and metabolomics were evaluated using liquid chromatography tandem mass spectrometry (LC-MS/MS) method by Novogene Bioinformatic Technology Co., Ltd. (Beijing, China). The detailed protocols are described in Supplementary Material and Methods. The supernatants from NBRIP medium inoculated with the same amount of LB were used as negative control.

\section{Cloning and Expression of the Ac-14 gcd}

The genome of Acinetobacter sp. Ac-14 was sequenced by PacBio's Single Molecule Real-Time (SMRT) sequencing technology. The sequence was submitted to NCBI GenBank (accession number CP063769). The gcd gene (2,406 bp, in Supplementary Material and Methods) was amplified via PCR using primers GCD-F (5'-agaattcatgaatcaaccta cttcaagatcagg- $3^{\prime}$, underlined is EcoRI site) and GCD-R ( $5^{\prime}$ aggatccttatttgttatctggtaaggcataagcc- $3^{\prime}$, underlined is Bam $\mathrm{HI}$ site). For expression vector, the $g c d$ was cloned into pBBR1MCS2 plasmid $^{1}$. The recombinant plasmid was then introduced into Pseudomonas sp. Ps-12. Ps-12 carrying the recombinant plasmid pBBR1MCS-2-gcd was named Ps-12 (gcd). The phosphatesolubilizing ability, $\mathrm{pH}$ value, and $A_{600}$ value of Ps-12 or Ps-12 (gcd) were detected in the NBRIP liquid medium.

\footnotetext{
${ }^{1}$ http://www.addgene.org/85168/
} 


\section{Determination of IAA and Ammonia of Ac-14}

The Ac-14 strain was incubated overnight in LB medium under $180 \mathrm{r} / \mathrm{min}$ at $28 \pm 2^{\circ} \mathrm{C}$. The bacteria were then collected via centrifugation at $5,000 \mathrm{r} / \mathrm{min}$ for $2 \mathrm{~min}$. After washing twice with LB liquid medium containing $5 \mathrm{mg} / \mathrm{mL}$ tryptophan, the suspension was inoculated into LB (containing $5 \mathrm{mg} / \mathrm{mL}$ tryptophan $)$ liquid medium $\left(A_{600}=0.1\right)$. Thereafter, the bacteria were incubated at $28 \pm 2^{\circ} \mathrm{C}$ and $180 \mathrm{r} / \mathrm{min}$ for $120 \mathrm{~h}$. Two $\mathrm{mL}$ of the culture was collected every $24 \mathrm{~h}$ and centrifuged at 12,000 $\mathrm{r} / \mathrm{min}$ for $1 \mathrm{~min}$. Next, $1 \mathrm{~mL}$ of supernatant was mixed with $2 \mathrm{~mL}$ of Salkowski's reagent $\left(2 \% \quad 0.5 \mathrm{M} \mathrm{FeCl}_{3}\right.$ in $35 \% \mathrm{HClO}_{4}$ solution) (Biswas et al., 2018). After reacting at room temperature under dark conditions for $30 \mathrm{~min}$, indole acetic acid (IAA) was determined by measuring $A_{530}$. The LB medium containing $5 \mathrm{mg} / \mathrm{mL}$ tryptophan was used as negative control.

The collected bacteria were washed twice with peptone water (peptone $10 \mathrm{~g} / \mathrm{L}, \mathrm{NaCl} 5 \mathrm{~g} / \mathrm{L}, \mathrm{pH} 7.0 \pm 0.2$ ). The biomass was adjusted to $A_{600}=0.1$ using peptone water, and incubated under $180 \mathrm{r} / \mathrm{min}$ at $28 \pm 2^{\circ} \mathrm{C}$ for $120 \mathrm{~h}$. Culture samples were collected every $24 \mathrm{~h}$ and centrifuged at $12,000 \mathrm{r} / \mathrm{min}$ for $1 \mathrm{~min}$. The supernatant was then reacted with Nessler's reagent (Marques et al., 2010; Orhan, 2016) to determine ammonia by measuring $A_{420}$. Peptone water was used as a negative control.

\section{Statistical Analysis}

All the experiments concerning data comparisons were performed three times. Statistical analyses were performed using the S-N-K method of one-way ANOVA or independent samples $t$-test (95\% confidence) with IBM SPSS Statistics 22.0 (SPSS Inc., Chicago, IL, United States). Values with different lowercases represented a significant difference at $P<0.05$. * or ** indicated significant difference for the $t$-test $(P<0.05$ or $P<0.01)$.

\section{RESULTS}

\section{Isolation of PSB Strains From the Fruit Tree Rhizosphere Soil in KRD Regions}

In total, 805 PSB strains were isolated from 18 fruit tree rhizosphere soil samples. Of these, 570 PSB strains were from $\mathrm{KRD}$ regions in Southwest China, and 235 PSB strains were from the NKRD regions (Table 1). Moreover, 89 strains (67 and 22 strains from KRD and NKRD, respectively) with different colony morphologies and larger SI values were screened after $16 \mathrm{~S}$ rDNA sequencing. Pseudomonas sp. was present in both KRD and NKRD region soils, whereas Acinetobacter sp. and Paraburkholderia sp. only appeared in some soil samples of KRD regions (Table 1).

The phosphate-solubilizing ability of the 89 strains was evaluated by the Mo-blue method. Of these, 22 PSB strains could dissolve more than $300 \mathrm{mg} / \mathrm{L}$ of phosphate. Among these 22 strains, seven belonged to Acinetobacter, one belonged to Paraburkholderia, and 14 belonged to Pseudomonas (Supplementary Table S1). The Acinetobacter sp. Ac-14 isolated from the KRD region (GJ2, Yinjiang, Guizhou) revealed the highest phosphate-solubilizing ability.

One strain from each genus summarized in Supplementary Table S1 with the highest phosphate-solubilizing ability was selected for further study (Table 2). The colony morphology observation revealed that Acinetobacter sp. Ac-14 was white and circular with an SI of 2.37; Paraburkholderia sp. Pa-3 was white in the middle and translucent outside with an irregular edge and SI of 2.29; Pseudomonas sp. Ps-12 strain was yellow and circular with an SI of 1.66 (Supplementary Figure S1). The three strains were rod-shaped and gram-negative bacteria but were different sizes (Supplementary Figure S1). Phylogenetic tree by $16 \mathrm{~S}$ rDNA sequencing confirmed that the three strains belonged to different groups (Supplementary Figure S2).

\section{PSB Strains, Particularly Ac-14, Had Sustained and Stable Phosphate-Solubilizing Ability Even Under $\mathrm{CaCO}_{3}$ Condition}

To assess the phosphate-solubilizing characteristics of the isolated strains, their phosphate-solubilizing ability in liquid NBRIP medium, as well as the $\mathrm{pH}$ and bacterial $A_{600}$ values, were determined. As illustrated in Figure 1, for Ac-14, the soluble P concentration in the medium rapidly elevated within $12 \mathrm{~h}$, and then slowly increased between 12 and $48 \mathrm{~h}$, and was further maintained at a high level (439-448 mg/L, 48-120 h). The pH value of the medium dropped rapidly from 7.3 to 4.5 within $6 \mathrm{~h}$ and was then maintained at a low level. The growth of biomass rapidly elevated to 1.2 within $12 \mathrm{~h}$, and then slowly increased until it reached the stationary phase. Thus, the phosphate-solubilizing ability revealed a similar change as that of $A_{600}$, whereas it revealed an inverse relation with the $\mathrm{pH}$ value. Furthermore, the lowest $\mathrm{pH}$ value appeared earlier than that of the maximum value of soluble P content and $A_{600}$.

For Pa-3 (Figure 1), the soluble $\mathrm{P}$ concentration in the medium rapidly increased and further decreased, with the highest value $(365 \mathrm{mg} / \mathrm{L})$ at $24 \mathrm{~h}$; moreover, soluble $\mathrm{P}$ could not be detected at $72 \mathrm{~h}$. In contrast, the $\mathrm{pH}$ value rapidly decreased within $12 \mathrm{~h}$ and then increased. The growth of biomass rapidly elevated within $12 \mathrm{~h}$, then increased slowly, and then decreased slowly. The phosphate-solubilizing ability, $\mathrm{pH}$ value, and growth of biomass of Ps-12 revealed a similar change tendency to that of $\mathrm{Pa}-3$ (Figure 1).

As rocky desertification mainly occurs in carbonate rock areas, we studied the phosphate-solubilizing ability of the isolated PSB strains under $\mathrm{CaCO}_{3}$ condition (Figure 2). $\mathrm{CaCO}_{3}$ markedly decreased the phosphate-solubilizing ability of the strains, and its effect was increased as concentration increased. At a concentration of $2 \mathrm{~g} / \mathrm{L}$, soluble $\mathrm{P}$ could not be detected in the supernatant; however, Ac-14 still had a higher phosphatesolubilizing ability than Pa-3 and Ps-12 under each $\mathrm{CaCO}_{3}$ concentration condition. Under $0.5 \mathrm{~g} / \mathrm{L} \mathrm{CaCO}_{3}$ (Figure 3), the changes in the phosphate-solubilizing ability, $\mathrm{pH}$ value, and $A_{600}$ value of the three PSB strains were similar to those without $\mathrm{CaCO}_{3}$, except for the lower maximum phosphate-solubilizing abilities than those without $\mathrm{CaCO}_{3}$ (Figure 1). The effect of 
TABLE 2 | The colony characteristics of Acinetobacter sp. Ac-14, Paraburkholderia sp. Pa-3, and Pseudomonas sp. Ps-12 from KRD regions in Southwest China.

\begin{tabular}{|c|c|c|c|}
\hline Characteristics & Ac-14 & Pa-3 & Ps-12 \\
\hline Color & White & White in the middle with translucent around the outside & Yellow \\
\hline Surface & Glossy & Moist & Glossy \\
\hline Shape & Circular & Irregular edge & Circular \\
\hline Uplift/shape & Raised & Uneven & Flat \\
\hline Margin & Smooth & Smooth & Smooth \\
\hline SI value & $2.37 \pm 1.09$ & $2.29 \pm 0.39$ & $1.66 \pm 0.94$ \\
\hline Cell size $(\mu \mathrm{m})$ & $(0.58 \pm 0.05) \times(1.03 \pm 0.16)$ & $(0.49 \pm 0.04) \times(1.99 \pm 0.17)$ & $(0.54 \pm 0.06) \times(1.66 \pm 0.19)$ \\
\hline Gram character & Negative & Negative & Negative \\
\hline Genus (by 16S rDNA) & Acinetobacter & Paraburkholderia & Pseudomonas \\
\hline
\end{tabular}
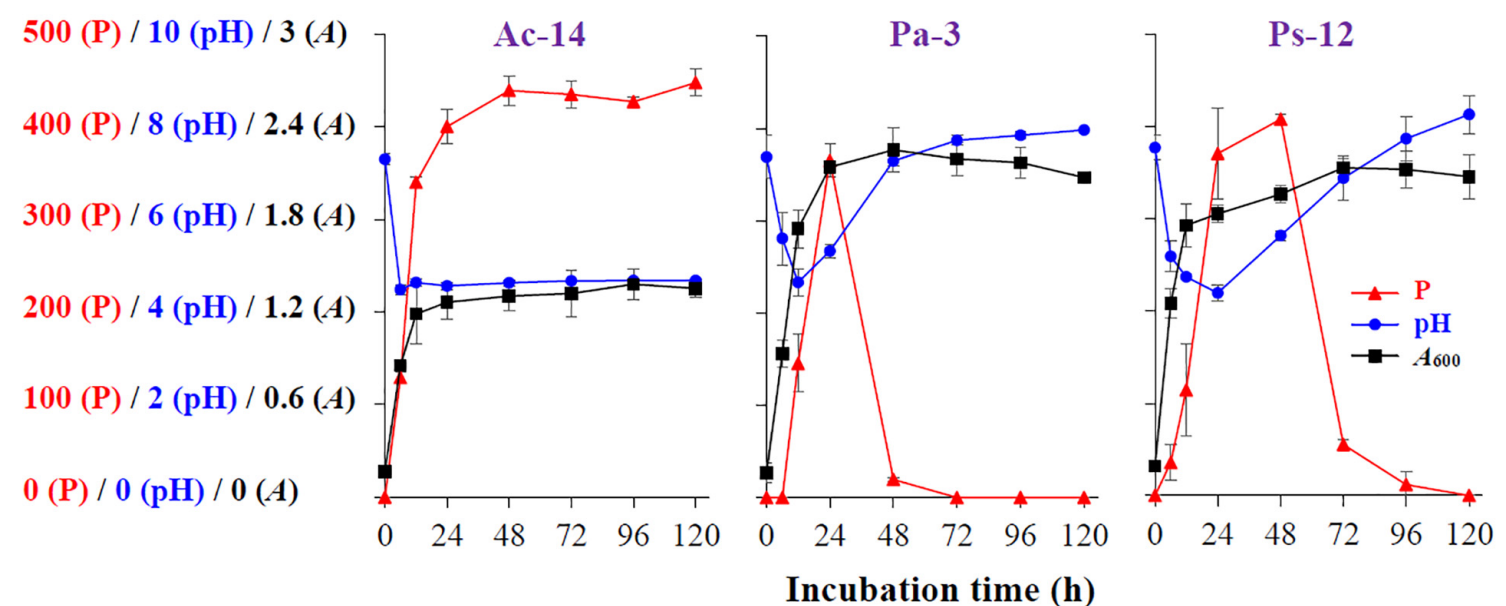

Incubation time (h)

FIGURE 1 | The time-curve of the soluble P content (P, mg/L), pH value (pH), and $A_{600}$ value $(A)$ of Acinetobacter sp. Ac-14, Paraburkholderia sp. Pa-3, and Pseudomonas sp. Ps-12.

$\mathrm{CaCO}_{3}$ on phosphate-solubilizing ability was limited in liquid medium, but not in agar-solidified medium (Supplementary Figure S3 and Supplementary Table S2).

Moreover, the effect of several insoluble phosphate sources on the phosphate-solubilizing ability of the aforementioned three PSB strains was studied. When $\mathrm{Ca}_{3}\left(\mathrm{PO}_{4}\right)_{2}$ was substituted with equal amounts of $\mathrm{AlPO}_{4}$ or $\mathrm{FePO}_{4}$ (data not shown) in liquid NBRIP medium, soluble $\mathrm{P}$ could not be detected in the medium inoculated with Ac-14, $\mathrm{Pa}-3$, and $\mathrm{Ps}-12$, thus indicating that the three strains can only dissolve $\mathrm{Ca}_{3}\left(\mathrm{PO}_{4}\right)_{2}$.

\section{Inoculation of Ac-14 to Roots of Arabidopsis thaliana Seedlings Promoted Vegetative Growth}

Since Ac-14, Pa-3, and Ps-12 had a strong ability to dissolve phosphate, their effect on plant growth needs to be explored. Therefore, we inoculated the strains in the roots of $A$. thaliana seedlings and observed the growth status. When Ac-14 was cocultured for 7 days, the number of lateral roots, fresh weight, and chlorophyll content began to increase; however, no change was observed in the primary root length (Supplementary Figures S4A-D). On the 14th day, the seedlings inoculated with Ac-14 grew vigorously and had developed lateral roots (Figure 4A).
The fresh weight was increased 6.5-fold, and the chlorophyll content increased 46.5-fold (Figures 4B,C), compared to that without inoculation, thus indicating that Ac-14 could remarkably promote the growth of $A$. thaliana seedlings. Pa- 3 and Ps- 12 were also effective but had a lesser impact on the growth of $A$. thaliana seedlings compared to that of Ac-14.

We further assessed the effect of Ac-14 on the growth of A. thaliana seedlings in a medium containing $0.5 \mathrm{~g} / \mathrm{L} \mathrm{CaCO}_{3}$. The seedlings inoculated with Ac-14 presented remarkable growth when cocultured for 7 days compared to that without Ac-14 (Supplementary Figures S4E-H). On the 14th day, the fresh weight of the seedlings inoculated with Ac-14 increased 2.1-fold, while the chlorophyll content increased 5-fold, compared to that without inoculation (Figure 5). These results indicated that inoculation of Ac-14 in the roots of Arabidopsis seedlings could promote vegetative growth in the presence and absence of $\mathrm{CaCO}_{3}$.

\section{Ac-14 Produced 23 Types of Organic Acids, While Gluconic Acid and D-(-)-Quinic Acid Increased Mostly}

To detect the metabolites of Ac-14 related to phosphate solubilization, we performed untargeted metabolomics 


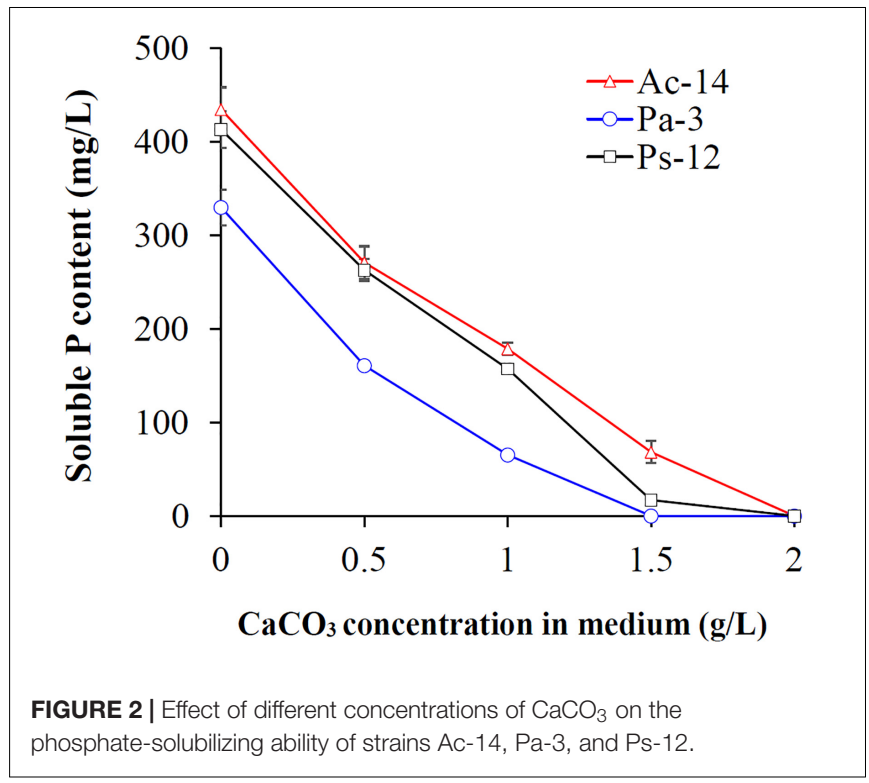

(Supplementary Figure S5). In total, 752 metabolites were detected; of these, 294 metabolites were detected under LCMS/MS (ESI-) scan model, whereas 458 metabolites were detected under LC-MS/MS (ESI+) scan model (see sheet "All metabolites" in Supplementary Excel S1). According to fold change $\geq 1.5$ or $\mathrm{FC} \leq 0.667$, VIP $>1$, and $P$-value $<0.05,124$ differential metabolites were identified in Ac-14 compared to that without inoculation; of these, 56 metabolites (37 metabolites were significantly increased and 19 metabolites were significantly decreased) were detected under ESI- model, and 68 metabolites (30 metabolites were significantly increased and 38 metabolites were significantly decreased) were detected under ESI+ model (Supplementary Figure S5; sheet "Differential metabolites" in Supplementary Excel S1). As organic acids were produced during bacterial phosphate solubilization, the differences in organic acids were further analyzed. Ac-14 could produce 23 types of organic acids (13 kinds of organic acids were increased under ESI- model and 10 kinds of organic acids were increased under ESI+ model) with the concentration increasing from 4.1-fold to 462.2-fold. Among these organic acids, gluconic acid (366-fold) and D-(-)-quinic acid were remarkably increased (462-fold) (Table 3). These results indicated that Ac-14 could produce abundant organic acids.

\section{Expression of Ac-14 gcd Gene Conferred Ps-12 With Sustained and Stable Phosphate-Solubilizing Ability}

To confirm the phosphate-solubilizing ability of Acinetobacter sp. Ac-14 related with gluconic acid, we cloned the Ac-14 gcd gene and expressed it in Pseudomonas sp. Ps-12. As illustrated in Figure 6, expression of $g c d$ gene in Ps-12 could maintain a sustained and stable soluble $\mathrm{P}$ concentration $(448 \mathrm{mg} / \mathrm{L}$, $48 \mathrm{~h} ; 438 \mathrm{mg} / \mathrm{L}, 120 \mathrm{~h}$ ), whereas Ps-12 without $\mathrm{gcd}$ revealed a maximum soluble $\mathrm{P}$ level at $48 \mathrm{~h}(393 \mathrm{mg} / \mathrm{L})$, then gradually decreased, and was further undetected at $120 \mathrm{~h}$. As a result,

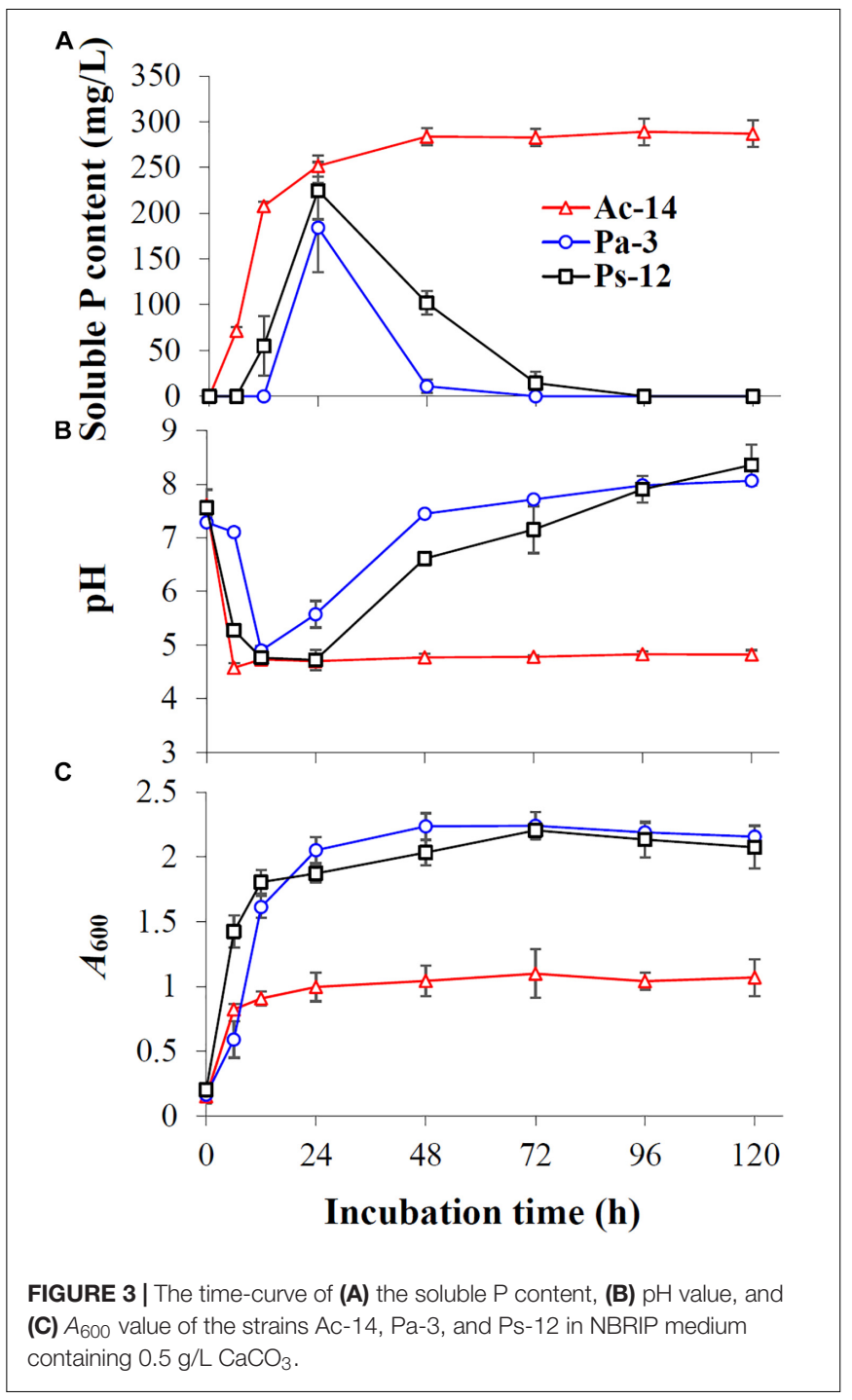

Ps-12 with $g c d$ could maintain a lower $\mathrm{pH}$ (4.1-4.2) during the experiment period; however, that without $g c d$ presented decreased $\mathrm{pH}$ within $24 \mathrm{~h}$, which then gradually increased. Ps12 with $g c d$ had a lower biomass than that without $g c d$. These results confirmed that the production of gluconic acid is an important mechanism conferred on bacteria with sustained and stable phosphate solubilization.

\section{Phosphate Solubilization of Ac-14 Did Not Occur via $\mathrm{NH}_{4}{ }^{+}$Assimilation}

$\mathrm{NH}_{4}{ }^{+}$assimilation can release protons and results in a decreased $\mathrm{pH}$. Whether the sustained and stable phosphate-solubilizing ability of Ac-14 is related to $\mathrm{NH}_{4}{ }^{+}$assimilation remains unclear. Hence, the phosphate-solubilizing ability, $\mathrm{pH}$ value, and $A_{600}$ value under different nitrogen sources $\left[\left(\mathrm{NH}_{4}\right)_{2} \mathrm{SO}_{4}, \mathrm{NH}_{4} \mathrm{Cl}\right.$, $\mathrm{NaNO}_{3}$, or $\mathrm{KNO}_{3}$ ] were determined. No significant difference was observed under different nitrogen sources (Supplementary Figure S6), indicating that the phosphate-solubilizing ability of Ac-14 did not occur due to $\mathrm{NH}_{4}{ }^{+}$assimilation. 

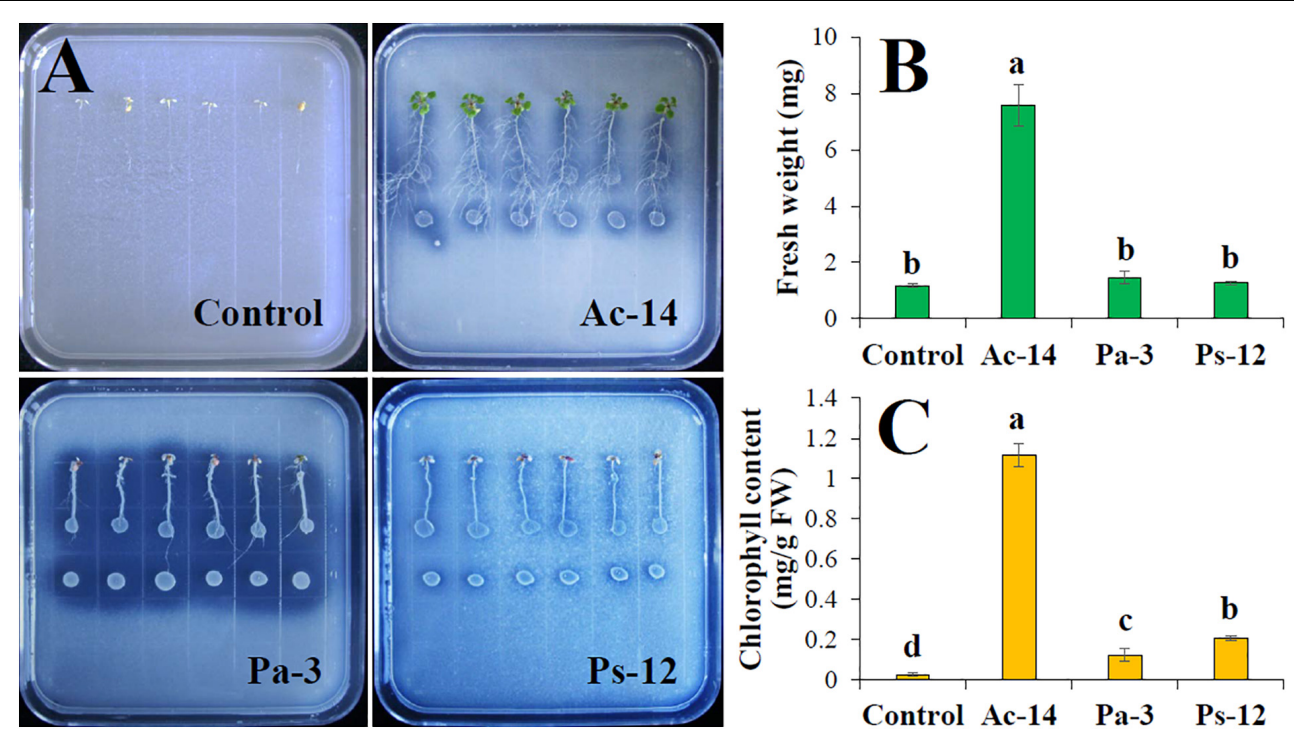

FIGURE 4 | Effects of the strains Ac-14, Pa-3, and Ps-12 on the growth of Arabidopsis thaliana seedlings in NBRIP agar-solidified medium (cocultivation for 14 days). (A) The growth status, (B) fresh weight per plant, and (C) chlorophyll content of $A$. thaliana. Different lowercase letters indicated statistically significant differences $(P<0.05)$.

\section{Ac-14 Produced IAA and Ammonia}

Whether other mechanisms besides phosphate solubilization are involved in the growth promoting effect of Ac-14 remains unclear. Hence, the plant growth promoting traits (like production of IAA and ammonia) for Ac-14 were detected. IAA was increased with the incubation time, and the concentration reached $25.1 \mathrm{mg} / \mathrm{L}$ at $120 \mathrm{~h}$. Furthermore, ammonia was also increased and then maintained at a stable level during the incubation period, and the concentration was $231 \mathrm{mg} / \mathrm{L}$ at $120 \mathrm{~h}$ (Figure 7).

\section{Ac-14 Grew in a Wide Range of pH}

As Ac-14 can produce organic acids, the environmental $\mathrm{pH}$ range it can withstand remains unclear. Hence, the growth status of Ac-14 under different $\mathrm{pH}$ values was explored (Supplementary Figure S7). The strain grew best at $\mathrm{pH} 5-7$, and the $A_{600}$ value was approximately 2.3. At $\mathrm{pH} 8-9, A_{600}$ value was approximately 2.2. When $\mathrm{pH}$ was 4.5 or $10, A_{600}$ value was about 2.1 . When $\mathrm{pH}$ was 11 , the growth of the strain was severely affected and $A_{600}$ value was only 0.12 . When $\mathrm{pH}$ was less than 4 or greater than 12, the bacteria could not grow. This result indicated that Ac-14 could grow at various $\mathrm{pH}$ ranges.

\section{DISCUSSION}

\section{Acinetobacter sp. Ac-14 With Phosphate-Solubilizing Ability Was Successfully Isolated From KRD Soil}

$\mathrm{P}$ is an important macro-element in plant nutrition. PSB can transform insoluble $\mathrm{P}$ into an available form in the soil and has immense applications in ecoagriculture. Due to the limitations of microbial ecological adaptability, the utilization of native microorganisms to develop biological fertilizer has obvious advantages (Wang et al., 2018). Therefore, it is important to isolate PSB that efficiently dissolves phosphate and promotes plant growth from KRD soil samples. In this study, 805 PSB strains were isolated from the rhizosphere soil of fruit trees. Of these, 570 were from 15 soil samples in the KRD regions in Southwest China, while 235 were isolated from three soil samples from NKRD regions. Further analysis revealed that Acinetobacter sp. and Paraburkholderia sp. were uniquely distributed in fruit tree rhizosphere soil of KRD regions. Acinetobacter sp. Ac-14 could efficiently dissolve phosphate and promote plant growth. Therefore, Ac14 has a potential application in ecological restoration and development in KRD regions.

Previous studies reported that Pseudomonas, Bacillus, and Rhizobium are the most efficient phosphate solubilizers (Rodríguez and Fraga, 1999). In recent years, Acinetobacter was reported to have a high phosphate-solubilizing ability. Acinetobacter calcoaceticus YC-5a has a strong ability for solubilizing insoluble phosphate by producing organic acid and some plant growth-promoting factors such as IAA and siderophores. Moreover, this bacterium exhibits strong resistances to lead and antibiotics (Ren et al., 2013). Acinetobacter sp. YU-SS-SB-29, isolated from monazite sand, exhibits high phosphate solubilization and tolerance to uranium (Sowmya et al., 2014). Furthermore, Acinetobacter was also reported to effectively degrade toxic organic compounds (Li et al., 2020). In this study, Acinetobacter sp. Ac-14 isolated from fruit tree rhizosphere soil of KRD region had a high phosphate-solubilizing ability, further confirming that Acinetobacter can dissolve phosphate. Whether the bacterium is capable of resisting 

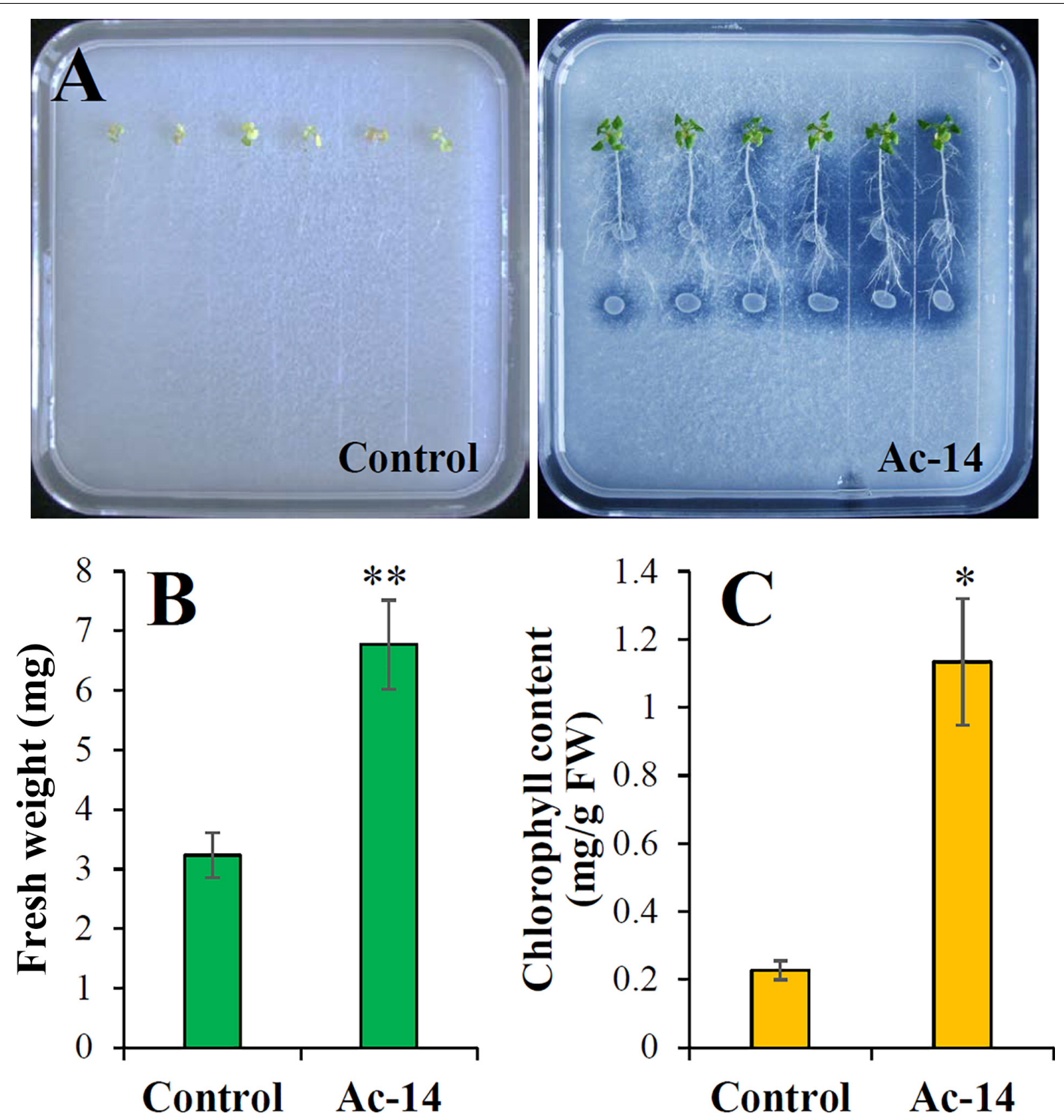

FIGURE 5 | Effect of Acinetobacter sp. Ac-14 on the growth of Arabidopsis thaliana seedlings in NBRIP agar-solidified medium containing 0.5 g/L CaCO 3 (cocultivation for 14 days). (A) The growth status, (B) fresh weight per plant, and (C) chlorophyll content of $A$. thaliana. ${ }^{\star} P<0.05$; ${ }^{\star \star} P<0.01$.

metal and degrading toxic organic compounds needs to be further studied.

\section{Production of Gluconic Acid Is the Core Mechanism of Ac-14 During Phosphate Solubilization}

The mechanisms of PSB involved in phosphate solubilization are complex, and various mechanisms have been proposed; of these, low $\mathrm{pH}$ is common. In the present study, Ac-14 revealed efficient, sustained, and stable phosphate-solubilizing ability, with the $\mathrm{pH}$ value was maintained at a low level. These findings are in accordance with previous studies (Lin et al., 2006; Wang et al., 2019). For Pa-3 and Ps-12, the phosphate-solubilizing ability was initially increased and then decreased with the incubation time, whereas the $\mathrm{pH}$ value was initially decreased and then increased. Therefore, the phosphate solubilization mechanism of these three strains may relate to $\mathrm{pH}$ changes; however, the changes occurring in the three strains are not exactly the same, thereby indicating differences in the mechanism of phosphate solubilization. Similar changes of $\mathrm{pH}$ and phosphate solubilization to that of $\mathrm{Pa}-3$ and $\mathrm{Ps}-12$ were reported previously (Teng et al., 2019). The maximum $A_{600}$ of Ac-14 was remarkably lower than that of $\mathrm{Pa}-3$ and Ps-12, which was presumably because low $\mathrm{pH}$ in the environment inhibited bacterial proliferation. In the NBRIP liquid medium containing $\mathrm{CaCO}_{3}$, the phosphatesolubilizing ability of the three PSB strains was decreased. This may occur because abundant $\mathrm{Ca}^{2+}$ combined with soluble $\mathrm{P}$ to form insoluble phosphate; however, the changed tendencies of phosphate-solubilizing ability, $\mathrm{pH}$ value, and $A_{600}$ under 
TABLE 3 | Comparison of organic acids between cultures inoculated with Acinetobacter sp. Ac-14 and non-inoculation under LC-MS/MS.

\begin{tabular}{|c|c|c|c|c|}
\hline Name & FC & $P$-value & VIP & ESI-/+ \\
\hline D-(-)-quinic acid & 462.2 & 3.17E-05 & 4.7 & + \\
\hline Gluconic acid & 366.0 & 3.13E-05 & 3.7 & - \\
\hline Indole-5-carboxylic acid (98\%) & 142.5 & $1.98 \mathrm{E}-04$ & 3.1 & - \\
\hline D-galactonic acid & 119.8 & $1.82 \mathrm{E}-05$ & 3.7 & + \\
\hline Pyrophosphate & 111.1 & 8.50E-06 & 3.0 & - \\
\hline (R)-lipoic acid & 60.5 & $1.82 \mathrm{E}-04$ & 3.2 & + \\
\hline Mesaconic acid & 51.6 & 7.52E-04 & 2.5 & - \\
\hline 2-methylsuccinic acid & 40.5 & $1.75 \mathrm{E}-03$ & 2.9 & + \\
\hline Indole-3-lactic acid & 39.0 & $2.08 \mathrm{E}-05$ & 2.3 & - \\
\hline 2-hydroxy-2-methylbutanedioic acid & 34.9 & 2.09E-03 & 2.2 & - \\
\hline 6-phosphogluconic acid & 32.6 & 8.44E-04 & 2.7 & + \\
\hline 2-(2-hydroxy-3-methylbutanamido)-4-methylpentanoic acid & 27.2 & 8.80E-05 & 2.5 & + \\
\hline Kojic acid & 16.5 & $1.71 \mathrm{E}-03$ & 2.2 & + \\
\hline Kinic acid & 15.5 & $6.28 \mathrm{E}-04$ & 1.7 & - \\
\hline Suberic acid & 12.1 & $1.77 \mathrm{E}-03$ & 1.6 & - \\
\hline 2-(acetylamino)-4-(methylthio) butanoic acid & 9.7 & $7.48 \mathrm{E}-04$ & 1.4 & - \\
\hline Uric acid & 9.1 & 8.48E-05 & 1.7 & + \\
\hline Elaidic acid & 7.6 & $5.72 \mathrm{E}-03$ & 1.3 & - \\
\hline 2-ketoadipic acid & 7.0 & 2.65E-02 & 1.3 & - \\
\hline 4-oxododecanedioic acid & 6.3 & $5.18 \mathrm{E}-04$ & 1.4 & + \\
\hline D- $\alpha$-Hydroxyglutaric acid & 5.9 & 1.09E-02 & 1.1 & - \\
\hline 3-[(methoxycarbonyl) amino]-2,2,3-trimethylbutanoic acid & 5.3 & 3.82E-03 & 1.1 & - \\
\hline 4-(2,3-dihydro-1,4-benzodioxin-6-yl) butanoic acid & 4.1 & 5.49E-04 & 1.1 & + \\
\hline
\end{tabular}

FC, fold change; P-value from univariate analysis (t-test); VIP, variable importance in the projection (VIP) value of the first principal component of PLS-DA model.
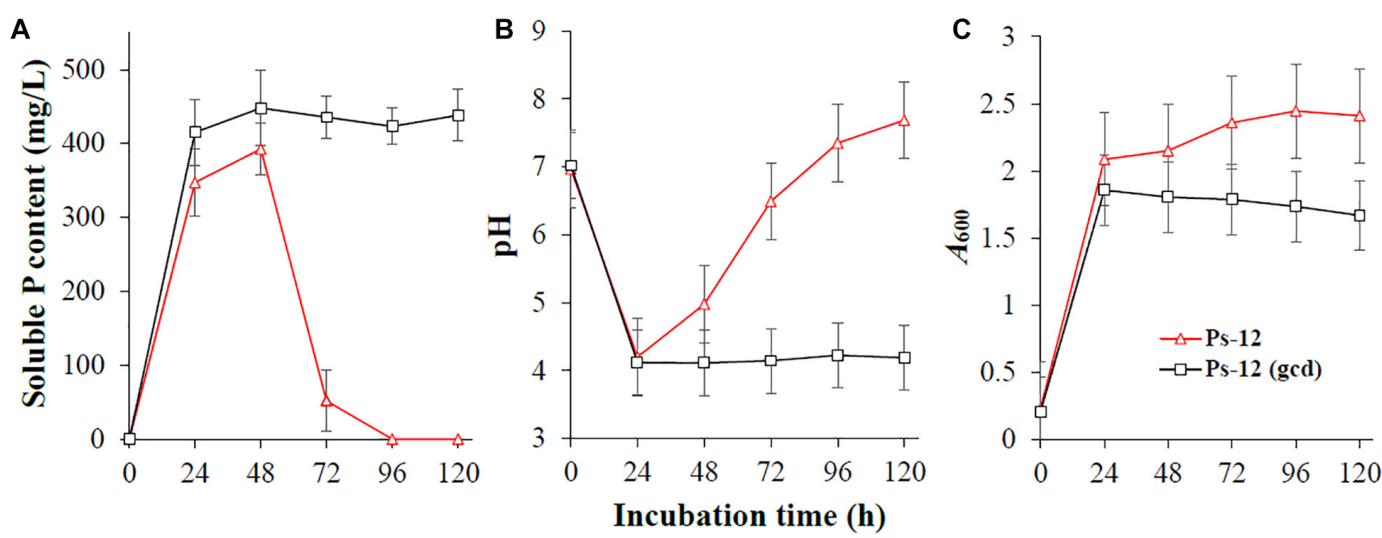

FIGURE 6 | The effects of Acinetobacter sp. Ac-14 gcd gene on (A) the soluble P content, (B) pH value, and (C) A600 value of Pseudomonas sp. Ps-12.

$\mathrm{CaCO}_{3}$ condition were almost similar to those without $\mathrm{CaCO}_{3}$. Interestingly, we also found that inhibition of $\mathrm{CaCO}_{3}$ did not affect the phosphate-solubilizing ability in the agar-solidified medium, which might be due to the poor mobility of $\mathrm{CaCO}_{3}$ in this medium. Therefore, application of PSB strains as biological fertilizers in the soil may not be affected by $\mathrm{CaCO}_{3}$ in $\mathrm{KRD}$ soils.

Furthermore, it was reported that low $\mathrm{pH}$ could occur due to production of organic acids and assimilation of $\mathrm{NH}_{4}{ }^{+}$(Rodríguez and Fraga, 1999; Sharma et al., 2013; Owen et al., 2015; Zhu et al., 2018). In this study, metabolomics analysis revealed that Ac-14 could substantially increase 23 types of organic acids; of these, gluconic acid, one of the most common organic acid metabolites (Lin et al., 2006; Rodríguez et al., 2006; Ludueña et al., 2018), was highly increased. It was reported that gram-negative bacteria produce gluconic acid during the extracellular oxidation of glucose through GCD (Liu et al., 1992; Goldstein, 1995), the lowered $\mathrm{pH}$ value and changed reduction potential are considered reasons for the dissolution of tricalcium phosphate (Lin et al., 2006). As a Gram-negative bacterium, Ac-14 may lower the $\mathrm{pH}$ value by producing gluconic acid, after excluding the possibility of $\mathrm{NH}_{4}{ }^{+}$assimilation. This was further demonstrated by the genetic engineering approach that suggested that Pseudomonas 

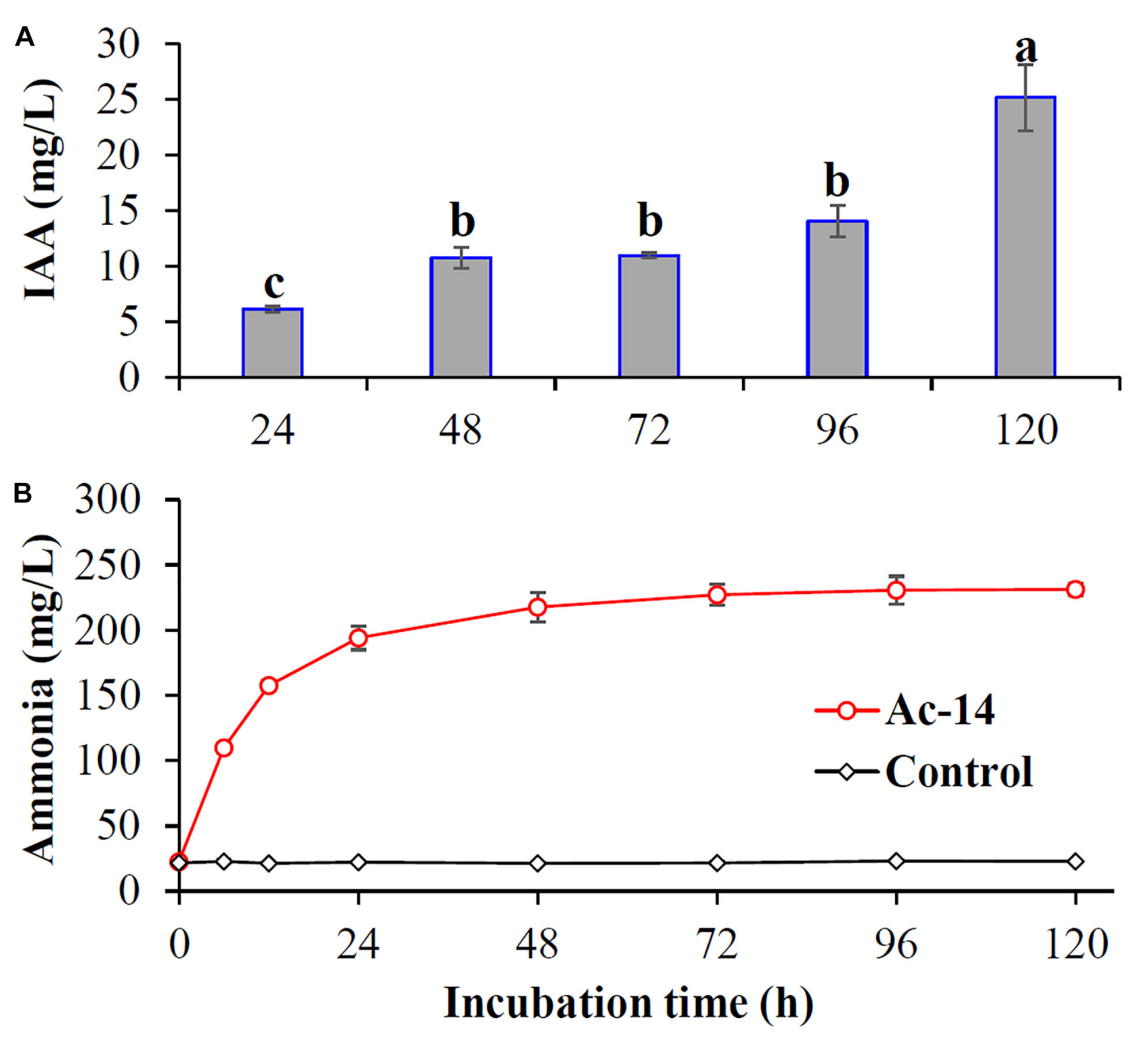

FIGURE 7| The content of (A) IAA and (B) ammonia produced by Acinetobacter sp. Ac-14. Different lowercase letters indicated statistically significant differences $(P<0.05)$.

sp. Ps-12 expressing Ac-14 gcd gene could maintain sustained and stable phosphate-solubilizing ability. Besides the common gluconic acid, D-(-)-quinic acid was also highly increased. D(-)-quinic acid is an efficient low molecular mass organic acid chelator. It can bind with metal ions (Menelaou et al., 2009) and acts as a metabolite with an antioxidant function (GargalloGarriga et al., 2015), which may confer the bacterium with tolerance and/or metal-degrading ability. The exact role of D-()-quinic acid in phosphate solubilization, and other mechanisms, needs to be further studied.

\section{Ac-14 Promotes the Growth of A. thaliana Seedling by Phosphate Solubilization and Produces IAA and Ammonia}

It was reported that PSB could promote the growth of numerous plants, such as Lolium perenne, Zea mays, Vigna radiata, Chinese cabbage, etc. (Owen et al., 2015; Biswas et al., 2018; Wang et al., 2019). In general, PSB enhances the root growth of plants and the yield of crops by increasing P availability (Sharon et al., 2016; $\mathrm{Ku}$ et al., 2018). In this study, we explored the effects of Ac14, Pa-3, and Ps-12 on the growth of $A$. thaliana seedlings. The number of lateral roots, fresh weight, and chlorophyll content were remarkably increased when $A$. thaliana was inoculated with Ac-14, whereas the leaves of $A$. thaliana without inoculation gradually turned white and died. However, not all PSB strains can promote plant growth (Bashan et al., 2013). In this study, $\mathrm{Pa}-3$ or Ps-12 could not significantly promote $A$. thaliana seeding growth. Furthermore, the process of insoluble P-solubilization is affected by several factors including soil type, nutritional richness of the soil, pH, moisture, and others (Rodríguez and Fraga, 1999; Chen et al., 2006; Alori et al., 2017; Wei et al., 2018). On the other hand, PSB would compete with other soil microflora (Wei et al., 2018). Whether Ac-14 could successfully colonize in KRD regions soil and exhibit phosphate-solubilizing ability and growth-promoting activities needs further research.

In this study, we revealed that the Ac-14 strain could produce certain growth-promoting substances such as IAA and ammonia. As a phytohormone, IAA promotes root growth to achieve a large surface area that facilitates nutrient absorption from the soil (Davies, 2010; Biswas et al., 2018; Wang et al., 2019). It was reported that some PSB strains, such as A. calcoaceticus YC5a, Bacillus sp., Staphylococcus sp., and Serratia sp. could also produce IAA (Ren et al., 2013; Biswas et al., 2018; Ludueña et al., 2018). Ammonia is a nitrogen source that can be taken up by plants and could promote plant growth. It was reported that all test strains isolated from plant root nodules of different rhizospheric soils in the vicinity of Aligarh could produce ammonia (Ahmad et al., 2008). Three PSB strains isolated from earthworms (Metaphire posthuma) could also produce ammonia (Biswas et al., 2018). Therefore, Ac-14 promoting 
A. thaliana seedling growth might also relate to the secretion of IAA and ammonia.

\section{CONCLUSION}

In this study, we isolated PSB strains from the fruit tree rhizosphere soil in the KRD regions in Southwest China. A novel PSB strain, Acinetobacter sp. Ac-14, presented efficient, sustained, and stable phosphate-solubilizing ability, and could also promote plant growth. The strain dissolved insoluble phosphate by producing 23 types of organic acids; of these, gluconic acid played an important role in the solubilization process. Ac-14 could also produce plant growth-promoting substances such as IAA and ammonia. Therefore, Ac-14 may adapt to the high calcium environment in KRD regions and has the potential to be utilized in improving the fertility of KRD regions.

\section{DATA AVAILABILITY STATEMENT}

The datasets presented in this study can be found in online repositories. The names of the repository/repositories and accession number(s) can be found in the article/ Supplementary Material.

\section{REFERENCES}

Ahmad, F., Ahmad, I., and Khan, M. S. (2008). Screening of free-living rhizospheric bacteria for their multiple plant growth promoting activities. Microbiol. Res. 163, 173-181. doi: 10.1016/j.micres.2006.04.001

Alori, E. T., Glick, B. R., and Babalola, O. O. (2017). Microbial phosphorus solubilization and its potential for use in sustainable agriculture. Front. Microbiol. 8:971. doi: 10.3389/fmicb.2017.00971

Bashan, Y., Kamnev, A. A., and de-Bashan, L. E. (2013). Tricalcium phosphate is inappropriate as a universal selection factor for isolating and testing phosphatesolubilizing bacteria that enhance plant growth: a proposal for an alternative procedure. Biol. Fertil. Soils 49, 465-479. doi: 10.1007/s00374-012-0737-7

Biswas, J. K., Banerjee, A., Rai, M., Naidu, R., Biswas, B., Vithanage, M., et al. (2018). Potential application of selected metal resistant phosphate solubilizing bacteria isolated from the gut of earthworm (Metaphire posthuma) in plant growth promotion. Geoderma 330, 117-124. doi: 10.1016/j.geoderma.2018.05.034

Chen, Y. P., Rekha, P. D., Arun, A. B., Shen, F. T., Lai, W. A., and Young, C. C. (2006). Phosphate solubilizing bacteria from subtropical soil and their tricalcium phosphate solubilizing abilities. Appl. Soil Ecol. 34, 33-41. doi: 10. 1016/j.apsoil.2005.12.002

Davies, P. J. (2010). "The plant hormones: their nature, occurrence, and functions," in Plant Hormones, ed. P. J. Davies (Dordrecht: Springer), 1-15. doi: 10.1007/ 978-94-011-0473-9_1

Gargallo-Garriga, A., Sardans, J., Pérez-Trujillo, M., Oravec, M., Urban, O., Jentsch, A., et al. (2015). Warming differentially influences the effects of drought on stoichiometry and metabolomics in shoots and roots. New Phytol. 207, 591-603. doi: 10.1111/nph.13377

Goldstein, A. H. (1995). Recent progress in understanding the molecular genetics and biochemistry of calcium phosphate solubilization by gram negative bacteria. Biol. Agric. Hortic. 12, 185-193. doi: 10.1080/01448765.1995.9754736

Jiang, Z., Lian, Y., and Qin, X. (2014). Rocky desertification in Southwest China: impacts, causes, and restoration. Earth Sci. Rev. 132, 1-12. doi: 10.1016/j. earscirev.2014.01.005

Ku, Y., Xu, G., Tian, X., Xie, H., Yang, X., Cao, C., et al. (2018). Root colonization and growth promotion of soybean, wheat and Chinese cabbage by Bacillus cereus YL6. PLoS One 13:e0200181. doi: 10.1371/journal.pone.0200181

\section{AUTHOR CONTRIBUTIONS}

$\mathrm{XC}$ and DC designed the experiments. JX, ZY, GW, WX, and CL performed the experiments. JX, ZY, and DC analyzed the data. JX, XC, and DC wrote the manuscript. All authors discussed the results and implications and commented on the manuscript at all stages.

\section{FUNDING}

This research was supported by the grants of the National Key Research and Development Program of China (2016YFC0502304-03), the Key Program of the Natural Science Foundation of Tianjin (18JCZDJC33700), and the National Natural Science Foundation of China (31870304 and 32070349).

\section{SUPPLEMENTARY MATERIAL}

The Supplementary Material for this article can be found online at: https://www.frontiersin.org/articles/10.3389/fmicb. 2020.625450/full\#supplementary-material

Li, Y., Lin, M., Ni, Z., Yuan, Z., Liu, W., Ruan, J., et al. (2020). Ecological influences of the migration of micro resin particles from crushed waste printed circuit boards on the dumping soil. J. Hazard. Mater. 386:121020. doi: 10.1016/j. jhazmat.2019.121020

Liang, J. L., Liu, J., Jia, P., Yang, T. T., Zeng, Q. W., Zhang, S. C., et al. (2020). Novel phosphate-solubilizing bacteria enhance soil phosphorus cycling following ecological restoration of land degraded by mining. ISME J. 14, 1600-1613. doi: 10.1038/s41396-020-0632-4

Lin, T. F., Huang, H. I., Shen, F. T., and Young, C. C. (2006). The protons of gluconic acid are the major factor responsible for the dissolution of tricalcium phosphate by Burkholderia cepacia CC-Al74. Bioresour. Technol. 97, 957-960. doi: 10.1016/j.biortech.2005.02.017

Liu, S. T., Lee, L. Y., Tai, C. Y., Hung, C. H., Chang, Y. S., Wolfram, J. H., et al. (1992). Cloning of an Erwinia herbicola gene necessary for gluconic acid production and enhanced mineral phosphate solubilization in Escherichia coli HB101: nucleotide sequence and probable involvement in biosynthesis of the coenzyme pyrroloquinoline quinone. J. Bacteriol. 174, 5814-5819. doi: 10.1128/ jb.174.18.5814-5819.1992

Ludueña, L. M., Anzuay, M. S., Angelini, J. G., McIntosh, M., Becker, A., Rupp, O., et al. (2018). Strain Serratia sp. S119: a potential biofertilizer for peanut and maize and a model bacterium to study phosphate solubilization mechanisms. Appl. Soil Ecol. 126, 107-112. doi: 10.1016/j.apsoil.2017. 12.024

Marques, A. P. G. C., Pires, C., Moreira, H., Rangel, A. O. S. S., and Castro, P. M. L. (2010). Assessment of the plant growth promotion abilities of six bacterial isolates using Zea mays as indicator plant. Soil Biol. Biochem. 42, 1229-1235. doi: 10.1016/j.soilbio.2010.04.014

Menelaou, M., Mateescu, C., Zhao, H., Rodriguez-Escudero, I., Lalioti, N., Sanakis, Y., et al. (2009). pH-specific synthetic chemistry and solution studies in the binary system of iron (III) with the alphahydroxycarboxylate substrate quinic acid: potential relevance to iron chemistry in plant fluids. Inorg. Chem. 48, 1844-1856. doi: 10.1021/ic80 0356v

Murphy, J., and Riley, J. P. (1962). A modified single solution method for the determination of phosphate in natural waters. Anal. Chim. Acta. 27, 31-36. doi: $10.1016 /$ s0003-2670(00)88444-5 
Nautiyal, C. S. (1999). An effcient microbiological growth medium for screening phosphate solubilizing microorganisms. FEMS Microbiol. Lett. 170, 265-270. doi: 10.1111/j.1574-6968.1999.tb13383.x

Orhan, F. (2016). Alleviation of salt stress by halotolerant and halophilic plant growth-promoting bacteria in wheat (Triticum aestivum). Braz. J. Microbiol. 47, 621-627. doi: 10.1016/j.bjm.2016.04.001

Owen, D., Williams, A. P., Griffith, G. W., and Withers, P. J. A. (2015). Use of commercial bio-inoculants to increase agricultural production through improved phosphrous acquisition. Appl. Soil Ecol. 86, 41-54. doi: 10.1016/j. apsoil.2014.09.012

Park, J. H., Bolan, N., Megharaj, M., and Naidu, R. (2011). Isolation of phosphate solubilizing bacteria and their potential for lead immobilization in soil. J. Hazard. Mater. 185, 829-836. doi: 10.1016/j.jhazmat.2010.09.095

Ren, Y. X., Zhu, X. L., Fan, D. D., Ma, P., and Liang, L. H. (2013). Inoculation of phosphate solubilizing bacteria for the improvement of lead accumulation by Brassica juncea. Environ. Technol. 34, 463-469. doi: 10.1080/09593330.2012. 701234

Rodríguez, H., and Fraga, R. (1999). Phosphate solubilizing bacteria and their role in plant growth promotion. Biotechnol. Adv. 17, 319-339. doi: 10.1016/s07349750(99)00014-2

Rodríguez, H., Fraga, R., Gonzalez, T., and Bashan, Y. (2006). Genetics of phosphate solubilization and its potential applications for improving plant growth-promoting bacteria. Plant Soil 287, 15-21. doi: 10.1007/s11104-0069056-9

Sharma, S. B., Sayyed, R. Z., Trivedi, M. H., and Gobi, T. A. (2013). Phosphate solubilizing microbes: sustainable approach for managing phosphorus deficiency in agricultural soils. Springerplus 2:587. doi: 10.1186/2193-18012-587

Sharon, J. A., Hathwaik, L. T., Glenn, G. M., Imam, S. H., and Lee, C. C. (2016). Isolation of efficient phosphate solubilizing bacteria capable of enhancing tomato plant growth. J. Soil Sci. Plant Nut. 16, 525-536. doi: 10.4067/S071895162016005000043

Sowmya, S., Rekha, P. D., and Arun, A. B. (2014). Uranium (VI) bioprecipitation mediated by a phosphate solubilizing Acinetobacter sp. YU-SS-SB-29 isolated from a high natural background radiation site. Int. Biodeter. Biodegr. 94, 134-140. doi: 10.1016/j.ibiod.2014.07.009

Tang, J., Tang, X., Qin, Y., He, Q., Yi, Y., and Ji, Z. (2019). Karst rocky desertification progress: soil calcium as a possible driving force. Sci. Total Environ. 649, 1250-1259. doi: 10.1016/j.scitotenv.2018.08.242

Teng, Z., Chen, Z., Zhang, Q., Yao, Y., Song, M., and Li, M. (2019). Isolation and characterization of phosphate solubilizing bacteria from rhizosphere soils of the Yeyahu Wetland in Beijing, China. Environ. Sci. Pollut. Res. 26, 33976-33987. doi: 10.1007/s11356-018-2955-5

Wang, S. J., Liu, Q. M., and Zhang, D. F. (2004). Karst rocky desertification in Southwestern China: geomorphology, landuse, impact and rehabilitation. Land Degrad. Dev. 15, 115-121. doi: 10.1002/ldr.592

Wang, X., Wang, C., Sui, J., Liu, Z., Li, Q., Ji, C., et al. (2018). Isolation and characterization of phosphofungi, and screening of their plant growthpromoting activities. AMB Expr. 8:63. doi: 10.1186/s13568-018-0593-4
Wang, X., Xie, H., Ku, Y., Yang, X., Chen, Y., Yang, N., et al. (2019). Chemotaxis of Bacillus cereus YL6 and its colonization of Chinese cabbage seedlings. Plant Soil 447, 413-430. doi: 10.1007/s11104-019-04344-y

Wei, Y., Zhao, Y., Shi, M., Cao, Z., Lu, Q., Yang, T., et al. (2018). Effect of organic acids production and bacterial community on the possible mechanism of phosphorus solubilization during composting with enriched phosphatesolubilizing bacteria inoculation. Bioresour. Technol. 247, 190-199. doi: 10. 1016/j.biortech.2017.09.092

Wei, Y., Zhao, Y., Wang, H., Lu, Q., Cao, Z., Cui, H., et al. (2016). An optimized regulating method for composting phosphorus fractions transformation based on biochar addition and phosphate-solubilizing bacteria inoculation. Bioresour. Technol. 221, 139-146. doi: 10.1016/j.biortech.2016.09.038

White, W. B. (1997). Thermodynamic equilibrium, kinetics, activation barriers, and reaction mechanisms for chemical reactions in Karst Terrains. Environ. Geol. 30, 46-58. doi: 10.1007/s002540050131

Xiang, W. L., Liang, H. Z., Liu, S., Luo, F., Tang, J., Li, M. Y., et al. (2011). Isolation and performance evaluation of halotolerant phosphate solubilizing bacteria from the rhizospheric soils of historic Dagong Brine Well in China. World J. Microb. Biot. 27, 2629-2637. doi: 10.1007/s11274-011-0736-0

Xie, J., Xue, W., Li, C., Yan, Z., Li, D., Li, G., et al. (2019). Water-soluble phosphorus contributes significantly to shaping the community structure of rhizospheric bacteria in rocky desertification areas. Sci. Rep. 9:18408. doi: 10.1038/s41598019-54943-z

Xu, N., Chu, Y., Chen, H., Li, X., Wu, Q., Jin, L., et al. (2018). Rice transcription factor OsMADS25 modulates root growth and confers salinity tolerance via the ABA-mediated regulatory pathway and ROS scavenging. PLoS Genet. 14:e1007662. doi: 10.1371/journal.pgen.1007662

Yu, L. Y., Huang, H. B., Wang, X. H., Li, S., Feng, N. X., Zhao, H. M., et al. (2019). Novel phosphate-solubilising bacteria isolated from sewage sludge and the mechanism of phosphate solubilisation. Sci. Total Environ. 658, 474-484. doi: 10.1016/j.scitotenv.2018.12.166

Zhu, F., Qu, L., Hong, X., and Sun, X. (2011). Isolation and characterization of a phosphate-solubilizing halophilic bacterium Kushneria sp. YCWA18 from Daqiao saltern on the coast of Yellow Sea of China. Evid. Based Complement. Alternat. Med. 2011:615032. doi: 10.1155/2011/615032

Zhu, J., Li, M., and Whelan, M. (2018). Phosphorus activators contribute to legacy phosphorus availability in agricultural soils: a review. Sci. Total Environ. 612, 522-537. doi: 10.1016/j.scitotenv.2017.08.095

Conflict of Interest: The authors declare that the research was conducted in the absence of any commercial or financial relationships that could be construed as a potential conflict of interest.

Copyright (c) 2021 Xie, Yan, Wang, Xue, Li, Chen and Chen. This is an open-access article distributed under the terms of the Creative Commons Attribution License (CC BY). The use, distribution or reproduction in other forums is permitted, provided the original author(s) and the copyright owner(s) are credited and that the original publication in this journal is cited, in accordance with accepted academic practice. No use, distribution or reproduction is permitted which does not comply with these terms. 